ISSN electrónico: 1885-5210

DOI: https://doi.org/10.14201/rmc202016e369378

\title{
LOS SERAFINES DE LA VIRUELA: 22 ÁNGELES (2016)
}

\section{Smallpox Seraphim: 22 ángeles (2016)}

\author{
Itza Nahomy GUTIÉRREZ FONSECA \\ Escuela de Enfermería. Cruz Roja Mexicana (México). \\ Correo electrónico: itza.nahomy@gmail.com
}

Fecha de recepción: 8 de septiembre de 2020

Fecha de aceptación: 11 de septiembre de 2020

Fecha de publicación: 29 de enero de 2021

\section{Resumen}

La epidemia de la viruela representó para la Corona española un asunto de salud de gran importancia por lo que organizó la primera campaña de vacunación en sus posesiones en Nueva España y Asia. El descubrimiento de la vacuna por parte del Dr. Jenner, impulsó al Dr. Francisco Xavier Balmis a realizar la que es considerada hoy, la primera misión de cooperación internacional. Su travesía a lo largo de las colonias en compañía de Isabel de Cendala y 22 niños portadores de la linfa de la viruela son protagonistas de la película.

Palabras clave: viruela; vacunación; Balmis; Cendala.

\section{Abstract}

The smallpox epidemic represented a health issue of great importance for the Spanish Crown, reason for which it organized the first vaccination campaign in all its possessions in New Spain and Asia. The discovery of the vaccine by Dr. Jenner prompted Dr. Francisco Xavier Balmis to carry out what is considered nowadays the first international cooperation mission. His journey through the colonies with the company of Isabel de Cendala and 22 children, all of them are the protagonists of this film.

Keywords: smallpox; vaccination; Balmis; Cendala. 
Título original: 22 ángeles.

Otros títulos: 22 Angos.

País: España.

Año: 2016.

Director: Miguel Bardem.

Música: Luis Ivars.

Montaje: Néstor Calvo.

Guion: Alicia Luna (basada en la novela de Almudena de Arteaga, Ángeles custodios).

Intérpretes: María Castro, Pedro Casablanc, Octavi Pujades, Carlos Santos, Felipe García Vélez, José Sospedra, Fran Nortes, Javier Mejía, Toni Misó.

Color: color.

Duración: 105 minutos.

Género: drama histórico.

Idioma original: español.

Productoras: Four Luck Banana, Sunrise Picture y Televisión Española (TVE)

Sinopsis: La película narra la primera expedición filantrópica internacional realizada para llevar la vacuna contra la viruela, enfermedad que había cobrado ya miles de vidas en territorios europeos y americanos. Emprendida por el Dr. Francisco Xavier Balmis, médico cirujano de la corte de Carlos IV y la enfermera Isabel de Cendala. Ambos reclutan a 22 niños expósitos, a quienes variolizaron para ser portadores de la cura a Nueva España y Filipinas.

Enlace: https://www.imdb.com/title/tt5471634/ ?ref_=ttfc_ql

Hablar de viruela hoy en día resulta más un asunto de los archivos históricos que de un conocimiento en la clínica por parte del personal médico. De acuerdo con la Organización Mundial de la Salud ${ }^{1}$ esta enfermedad fue erradicada en el mundo en 1980, un virus que asoló a la humanidad durante 3000 años. Cifra nada despreciable.

Una película como ésta, que narra hechos de gran relevancia para la medicina, se ve enriquecida con los datos histórico-literarios incluidos y apenas en forma de tributo a una de

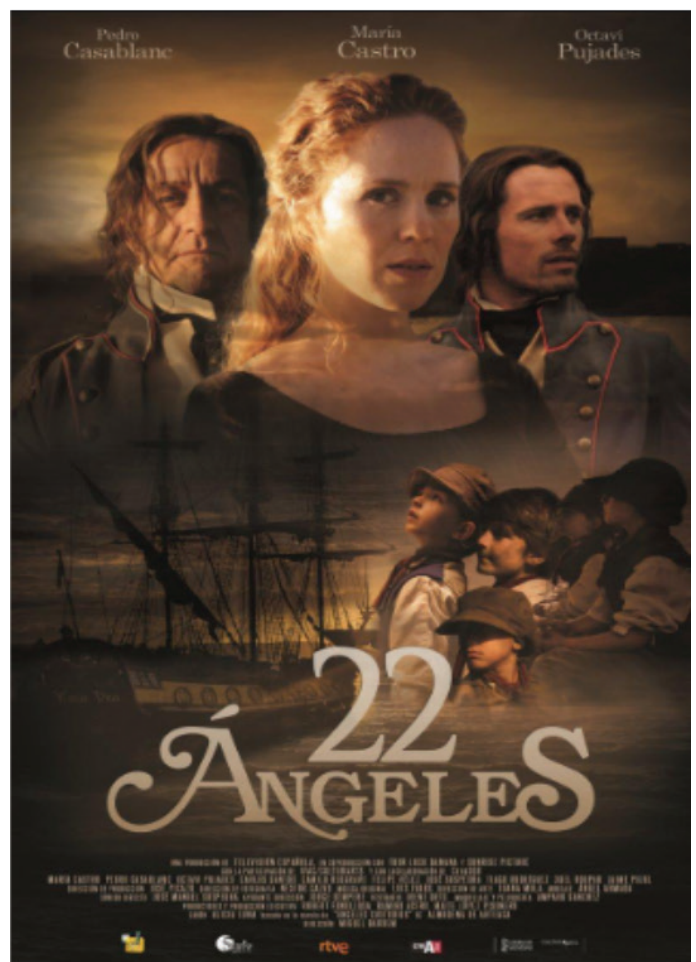

las empresas médicas más grandes de la humanidad. Si bien el filme muestra únicamente la primera fase del recorrido total de la Real Expedición Filantrópica de la Vacuna, no merma en nada su envergadura.

Por ello, cuando en 1770 el británico Edward Jenner, aún como estudiante de medicina, observó que las mujeres que ordeñaban a las vacas y habían contraído la viruela vacuna (cowpox) eran inmunes para desarrollar el virus (smallpox) comenzó a investigar sobre la ventaja inmunitaria de estas mujeres. No fue sino hasta 1796 cuando dispuso de un tipo de inoculación similar para utilizarse con las personas. Su vacuna pronto comenzó a emplearse y ello redujo los niveles de infectados en Europa y Estados Unidos. Si bien ya existía la variolación ${ }^{2}$, este nuevo método creado por el galeno facilitó su dispersión a lo largo y ancho del viejo continente, incluso, patrocinado por las 
monarquías europeas. Ello no estuvo exento de una amplia oposición a la invención jenneriana por parte de la comunidad médica y miembros notables de la sociedad, especialmente la inglesa. Entre estos últimos, se encontró al distinguido economista Robert Malthus.

A finales del siglo XVIII, diversos miembros de la familia real borbónica como la soberana María Ana Victoria; la hija del rey, la reina María Luisa; la princesa de Parma, el hermano del rey y su cuñada enfermaron del terrible mal, todos ellos sobrevivieron, lo cual no era común. La esposa del monarca lo alentó para que todos los integrantes de la realeza fueran variolizados. Frente al éxito del procedimiento, el 30 de noviembre de 1798 se decretó que toda la población civil debería ser tratada para prevenir la viruela ${ }^{3}$.

Las epidemias que atacaron a Bogotá en 1782, a la Ciudad de México en 1797 y al del Caribe en $1802^{4}$ influyeron para que la Corona española, encabezada por Carlos IV, decidiera la formación de una cruzada sanitaria en las colonias de su posesión. La experiencia de siglos atrás con la viruela, había demostrado la necesidad de contener su propagación, de lo contrario, el número de muertos sería alto. El médico de la corte, el Dr. José Felipe de Flores, de origen chiapaneco, recomendó al rey junto con el apoyo del clero católico, enviar un barco con la vacuna a los territorios de la Nueva España.

Es con la enfermera Isabel de Cendala ${ }^{a}$ con quien da principio la película, la vemos cubriendo los cuerpos de dos personas fallecidas a consecuencia de la viruela; de uno de ellos, se revelan las ámpulas características de la enfermedad. Sus cadáveres son incinerados para evitar mayores contagios. De Cendala sabemos que se queda a cargo del orfanato porque la madre responsable debe acudir a otros menesteres. La actividad servicial de Isabel y sus dotes de administración, le valen el puesto. $Y$ es que la vida en el hospicio no era sencilla, ya con 100 críos de diferentes edades, las carencias de comida, ropa, padres y la salud en vilo, asumirse como rectora ya implicaba un desafío.

Al avanzar el filme, Isabel de Cendala tiene el primer encuentro con Benito, cuya relación es muy cercana. El libro de Almudena de Arteaga ${ }^{6}$, base para la película, dice:

Siempre que alguno destacaba en mis afectos de entre los demás, conscientemente lo separaba de mi querer. Porque yo ya quise a mi hijo y para mí amar había sido el sinónimo de sufrir; algo que no quería padecer de nuevo porque ya no me quedaban lágrimas que derramar. Lo había conseguido hasta entonces, pero aquel niño era diferente. Se parecía tanto a mi Benito.

Tanto en el libro como en el filme, este niño queda huérfano y es el hospicio quien lo acobija. Datos recientes sobre la biografía de Cendala nos señalan que Isabel llegó a trabajar directamente al orfelinato, en sustitución de la rectora anterior, el 24 de marzo de 1800 con un sueldo de 50 reales. Un año después "recibirá media libra diaria de pan para su hijo y, desde agosto, media libra de carne al día"5 adicionales a los 16 reales por la compostura de ropas usada y remiendos de las vestimentas para los hospicianos. Por supuesto, los cuidados de la salud de los niños también se encontraban entre sus actividades.

La siguiente escena se desarrolla en el Consejo de Indias, donde el Dr. Balmis y el Dr. Ibáñez exponen las razones para emprender la campaña de vacunación, así como el método para transportar la linfa de forma segura: de brazo a brazo con los niños.

a. No existe consenso sobre la ortografía del apellido, puede encontrarse como Isabel de Zendal, de Zendala, Cendala, Cendal, Sendales, Sendal, etc. Se ha comentado que existen 35 versiones diferentes para designar a la misma persona ${ }^{5}$.

Rev. Med. Cine. 2020; 16 (e), 369-378 Ediciones Universidad de Salamanca / @®@@ J. Med. Mov., 2020; 16 (e), 369-378 [ 371 ] 
Como lo ocurrido con Jenner, las resistencias para ampliar los beneficios de la inoculación tuvieron sus pretextos en la financiación de tan gran proyecto. Tanto en el caso inglés como el español, fue gracias al apoyo de la monarquía que se dispuso de los fondos de la hacienda pública para realizar estas promociones a la salud.

Fue el 28 de junio de 1802 cuando se signa el Edicto Real que autorizó la travesía. El Consejo de Indias nombró al Dr. Francisco Xavier Balmis como director de la Real Expedición Filantrópica de la Vacuna. Y así como en la película, el ministro Godoy le urge al médico apresurar la organización de la travesía para evitar la ferocidad de los comerciantes para lucrar con la vacuna, Tuells ${ }^{7}$ lo confirma que en apenas 8 meses fueron tramitados todos los menesteres para la transportación y manutención de los viajeros ${ }^{8}$. (Figura 1 )

Para dicha misión reclutó al Dr. José Salvany, quien ejerció como subdirector; dos ayudantes, dos practicantes, uno de los cuales fue Francisco Pastor Balmis, sobrino del director; tres enfermeros, la única mujer de la comisión, la directora de la casa de los expósitos de La Coruña, Isabel de Cendala y los 22 niños, los ángeles portadores de la vacuna. Los nombres de los pequeños han sido inmortalizados en el monumento dedicado a esta hazaña sanitaria en el puerto de La Coruña (Figura 2).

El encuentro entre el Director de la Real Expedición y la Rectora del orfanato se da en medio de una conversación entorno a un libro: el Tratado histórico y práctico de la vacuna, de Moreau de la Sarthe, publicado en Francia en 1801 y que el propio Balmis había traducido para editarse justo a tiempo antes de zarpar y llevar los primeros 500 ejemplares impresos ${ }^{9}$. Y cuando Cendala externa su escepticismo respecto a la eficacia de la vacuna, el real cirujano no duda en responderle: lo crea usted o no, es una teoría más probada. Es tan categórico en esta afirmación

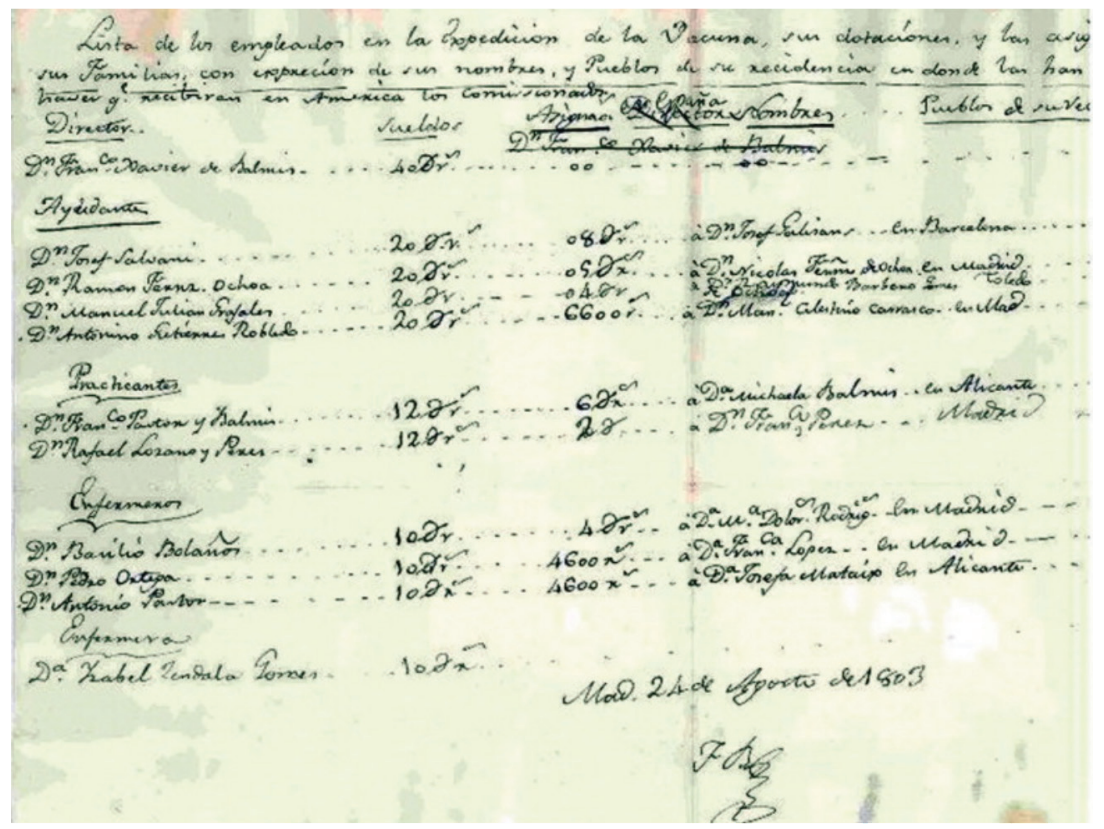

Figura 1. Lista de Balmis8. 


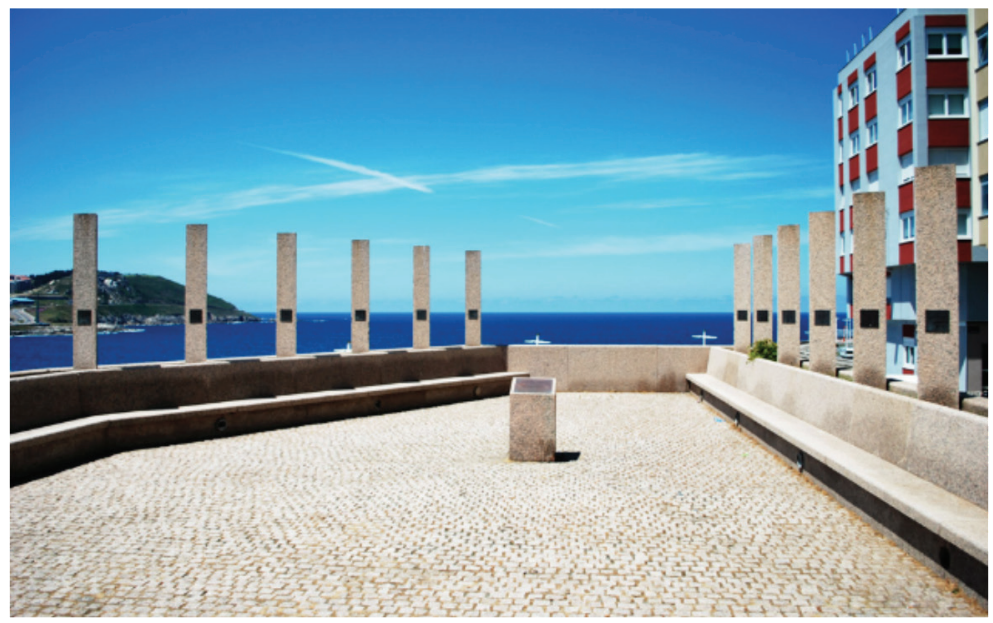

Figura 2. Monumento a la Real Expedición Filantrópica de la Vacuna en el puerto de La Coruña ${ }^{13}$.

porque ha traducido: "queda preservada la especie humana para siempre del contagio varioloso, sin que jamás se haya observado en más de 200,000 mil vacunados que ha habido, el menor peligro, ni resultado daño alguno" 10 .

Su presencia en La Coruña no es sólo para hablar de las ventajas de la inoculación, sino la urgencia de reunir a los niños portadores. Isabel es reacia, le parece más una acción mercantil que humanitaria. Sin embargo, el hospicio también necesita recursos y el Dr. Balmis le asegura las favorecedoras condiciones en las que estarán los infantes. Es entonces cuando la rectora acomete, junto con el Dr. Salvany, la búsqueda de sus ángeles. Las condiciones para embarcarlos fueron: tener entre 8 y 10 años y no haber padecido la viruela. El reclutamiento es doloroso y cruel al despedirse cada niño de sus familias. La autora De Arteaga ${ }^{6}$ revela algunos de los lugares de proveniencia de los críos: Santiago de Compostela, Santo Tomé, Santiago de Parderoa:

Por suerte... el capitán general del reino de Galicia, nos recibió sin cita previa. Su predisposición fue tanta que cuando ya nos íbamos, sin pedírselo siquiera, se comprometió a actuar conforme lo había hecho la hacienda de Madrid con los primeros niños de Balmis: donaría ocho reales por cada pequeño gallego que consiguiéramos... nuestros niños eran mejores que los de la capital.

Paralelamente a esta búsqueda, en la cinta se ve cómo en la antesala de la cámara real en Madrid se hacen intrigas para desmantelar la empresa del Dr. Balmis. Un grupo de cortesanos ha adelantado a tierras colombinas al Dr. Ibáñez, antiguo asistente del cirujano real, con una supuesta vacuna y con la promesa de montar su hospital de enfermedades tropicales. El ministro Godoy le hace saber al Dr. Balmis que es la reina directamente quien financia la campaña, y como prueba de ello, le extiende un broche con incrustaciones para que sea utilizado en caso de extrema necesidad. Así mismo, le informa que la orden real le será entregada antes de partir. Ello no ocurre y el tiempo apremia.

La corbeta María Pita (Fig. 3) es la destinada para transportar al grupo frente a la fragata $S i l p h^{8}$. Aunque de una capacidad menor, apenas 200 toneladas, son la velocidad y el coste más accesible, las razones para inclinarse por ella. 


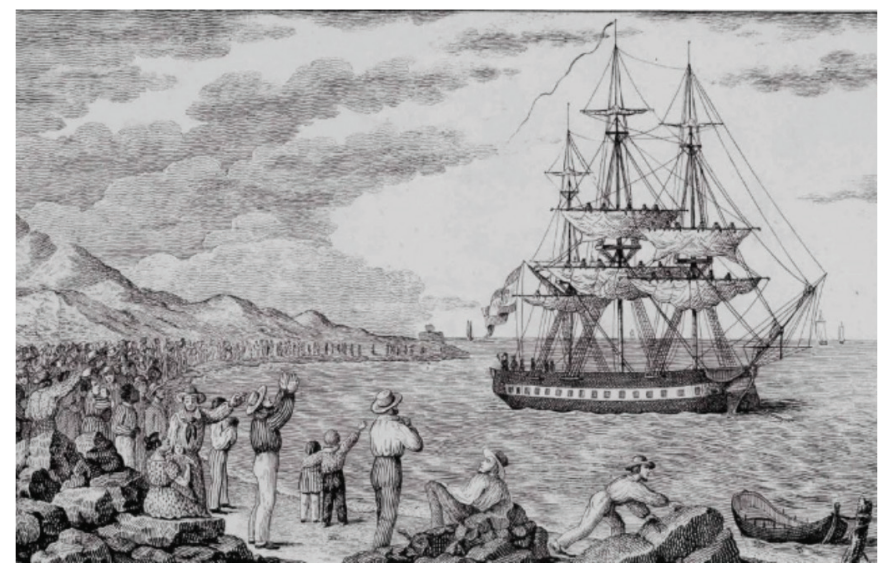

Fig. 3. Grabado del María Pita. Francisco Pére ${ }^{13}$.

Tanto en la película como en el libro Ángeles Custodios, Isabel parece embarcarse de último momento. Ello es necesario para darle un toque de emoción al relato de ficción. En la lista oficial entregada por Balmis el 24 de agosto de 1803 y que fue integrada tanto a la Orden Real como a la Gaceta de Madrid anunciando a todas las posesiones de ultramar sobre la Real Expedición, no aparece el nombre de la enfermera. Sin embargo, en una segunda lista (Figura 1) el nombre de Isabel de Cendala se encuentra escrito con el puño y letra del Dr. Balmis, incluso, señalando parte de sus obligaciones: "Para el buen desempeño de este cargo, conviene recaiga en sujetos de juicio y prudencia que cuiden del buen orden de los niños... de su limpieza y aseo... para conservar la salud y de asistirlos con amor y caridad"8.

Tuells ${ }^{8}$ explica este cambio de la siguiente forma. D. Ignacio Carrillo y Niebla ejercía como presidente del Hospital de la Caridad de La Coruña, del cual dependía la Casa de los Expósitos que Cendala dirigía. Es Carrillo quien propone a Balmis integrar a la rectora al grupo sanitario, primero para reunir a los niños y después, como la enfermera a cargo de ellos. Este tiempo del reclutamiento es el que le dará a Isabel la decisión de abordar el María Pita aunado a lo recientemente descubierto, que Benito -el último niño seleccionado- era su hijo biológico y no un expósito.

La corbeta zarpó del puerto de La Coruña el 30 de noviembre de 1803 con destino a las Islas Canarias $^{3}$. Durante el desarrollo de la película, Jonás, el letrado, aportará la cara opuesta de la bondad de la misión, intentando durante el viaje, sabotear el proyecto de salud, al querer envenenar a los niños.

Cabe hacer aquí un paréntesis. Entre el material médico embarcado, Pastor Balmis hace un listado de termómetros, barómetros, lancetas, jeringas y evidentemente, dos mil pares de vidrios que utilizarían para conservar la linfa que no reutilizasen de inmediato y la parafina para sellarlos ${ }^{6}$. El origen del fluido utilizado por el Dr. Balmis durante la travesía, fue obtenido, quizá, del stock provisto por el Dr. Luigi Sacco a la Corona española y quien era considerado como el Jenner de la vacuna en Italia. Sacco habría tomado las muestras de linfa de vacas suizas infectadas con el virus en 1800, y a partir de ahí, inició una campaña de vacunación a lo largo de Lombardía beneficiando a 8 mil personas para octubre de 1801. 
Estas tomas del virus del inventario de Sacco, fueron enviadas también a Jenner a Gran Bretaña, quien a su vez, las repartió al Dr. Ring y Dr. Woodville, con las que variolizaron parte del territorio británico. El médico suizo, Dr. Jean de Carro, utilizó tanto el líquido vacunal de Jenner, con el que emprendió campañas de vacunación en diversos territorios europeos, así como en Constantinopla y la linfa de Sacco, la trasladó a Bagdad y de ahí, en una cadena de brazo a brazo, al Dr. Helenus Scott, hasta la Indiab.

Es con este fluido del Dr. Sacco con el que vemos a Balmis realizar la incisión al primer niño para transmitir el virus y después recabar de las pústulas para otra toma y así sucesivamente entre los 22 niños. El médico real sabe que entre los síntomas luego del periodo de incubación de 12 días son la fiebre $\left(39-40{ }^{\circ} \mathrm{C}\right)$, cefalea, mialgias, postración con náuseas, vómitos y dolores de espalda. A la aparición del exantema en mucosa oral, el individuo es infeccioso ${ }^{11}$. Por eso cuando examina al primer chico inoculado, su estado febril le sugiere una reacción normal, sin embargo, presenta abdomen distendido y coloración en las yemas de los dedos, lo cual atribuye a un envenenamiento, que, por la sintomatología, se estima arsénico. El fallecimiento del pequeño desmoraliza a los tripulantes. A pesar de ello, continua el proceso de variolización.

La siguiente parada luego de las Canarias fue Puerto Rico, donde la corbeta arribó el 9 de febrero de 1804. La recepción no pudo ser menos áspera. Luego de navegar semanas y con las provisiones al límite, el mensajero eclesiástico les informa que por órdenes del Gobernador Ramón Castro deben abandonar aguas territoriales. La razón: ellos ya fueron vacunados con anticipación y su presencia no es bien vista.
Efectivamente, el Dr. Oller y Prieto había entregado a la demarcación linfa proveniente de la isla danesa Saint Thomas ${ }^{7}$. No fue la única ocasión en que la expedición encontró campañas previas de vacunación, aunque todas ellas, sin la efectividad necesaria. Ello se repitió en Cuba con el Dr. Romay, en México por los médicos García Arboleya, Serrano, Cozar, Pérez Carrillo, Pérez Comoto, Monzón y Murphy; en Guatemala, el propio Dr. Felipe de Flores, quien recomendó a Balmis como cabeza para la expedición, había realizado un trabajo arduo en aquella zona para ser continuado por el Dr. Esparragosa. En Perú fue el Dr. Belomo, mientras en Chile, el Dr. Chaparro.

El capitán del María Pita, al verse inhabilitado para el desembarque, considera el regreso a la península como la mejor opción ante la carencia de la orden real. Durante la cinta, el rumor de la muerte de una niña a consecuencia de la viruela días después de haberse vacunado, es la razón para que Balmis insista en proseguir, muestra el broche al capitán como la única prueba de las instrucciones reales. De Arteaga lo relata así:

Un muchacho del poblado de Yubucoa que al parecer había sido vacunado por Oller y aun así había caído enfermo. Le conocían como el Porrongo. Si aquello era verdad, nos bastaría para convencer al gobernador del posible fracaso de Oller. Sólo teníamos que probarlo.

La autora narra una contienda pública entre el Dr. Oller y Balmis para probar las diferencias entre ambas vacunas. Históricamente, esto no se realizó y la estancia en la isla boricua se redujo a lo necesario para reabastecer provisiones y conseguir 4 niños adicionales para variolizarlos e incorporarlos a la brigada. La expedición hubo de hacer un alto inesperado en Puerto Cabello, territorio venezolano, por dificultades en el mar ${ }^{4}$. Aunque sin estar en el programa del trayecto

b. Benbehani ${ }^{2}$ hace un recorrido muy preciso e interesante del proceso de variolización a lo largo del mundo y el papel de las monarquías para su diseminación. 
se aprovechó para vacunar a la localidad. EI comandante Pedro Suárez de Urbina apoyó para transmitir el fluido a 28 niños quienes se unieron al grupo original.

En la película, la expedición llegó a Cartagena, Colombia donde se encontraron con el virrey José Antonio Amar y de Borbón, quien los recibe abiertamente y al mismo tiempo, les requiere acciones inmediatas de su ministerio para dirigirse a la ciudad de Santa Fe, la cual es asolada por la peste y su vacuna es la única solución. Ante las órdenes del virrey, Balmis se ve obligado a escindir su caravana.

La historia describe que la Real Expedición Filantrópica de la Vacuna llegó a Caracas, proveniente de Puerto Cabello, el 28 de marzo de 1804 y fueron recibidos por el Capitán General Manuel de Guevara y Vasconcelos. Es aquí donde la comitiva sanitaria se divide para que Salvany inicie los trabajos de vacunación en Maracaibo y cruce por tierra hasta Quito, Ecuador el 16 de julio de 1805. Partió luego hacia Chile con el mismo objetivo. Su salud fue mermada en ese tiempo y finaliza sus días en Cochabamba, Bolivia el 21 de julio de 1810, probablemente de tuberculosis ${ }^{3,4}$.

La otra fracción del equipo sanitario, luego de un arduo trabajo en tierras venezolanas, navegó hacia Cuba, donde arribaron el 26 de mayo de 1804. Como ya se mencionó, el Dr. Romay ya había ejecutado actividades intensas de vacunación a lo largo de la isla. La linfa utilizada llegó de las mismas muestras aplicadas por Oller en Puerto Rico, aunque también, el propio Dr. Balmis le había enviado 2 niños puertorriqueños variolizados con el líquido traído desde ultramar. Las autoridades cubanas fueron receptivas al proyecto del Dr. Balmis.

Es así que, si ya en Caracas el director de la expedición se había asegurado de conformar un plan para dar seguimiento a su proyecto, es en La Habana donde se establece toda una estructura administrativa para dar continuidad al proceso de vacunación. Conforman las Juntas de Vacuna a cargo de cada región novohispana para realizar los censos de los vacunados, establecer la periodicidad para aplicar la vacuna, capacitar al personal para conseguir y mantener la efectividad de la linfa4.

El programa de Balmis es tan sólido en la creación de estas Juntas que fueron base para la creación del Programa Ampliado de Inmunización de la Organización Mundial de la Salud?.

Los viajeros de 22 ángeles, llegaron a la capital de la Nueva España el 9 de agosto de 1804. La recepción se nubló cuando encontraron al Dr. Ibáñez, aquel esbirro de los cortesanos españoles. El virrey José de Iturrigaray Aróstegui, no esconde su desprecio y, con sarcasmo invita a los expedicionarios a vacunar afuera de la catedral. Es Isabel de Cendala, en medio de la acalorada discusión, quien cuestiona a Ibáñez sobre la eficacia de una vacuna transportada en cristales y que ocasiona nuevos brotes de la enfermedad. La sorpresa es mayúscula al encontrar en el cuello del clérigo Arizmendi, las marcas de la viruela.

Balmis no sólo reprocha a su antiguo alumno distribuir una falsa vacuna, sino lucrarse con ella. Una de las prioridades del plan del cirujano real consistió siempre en la gratuidad de la vacuna. Por eso, su enfado es superior al enterarse de cuál ha sido el trabajo de Ibáñez en tierras americanas. El virrey gira instrucciones para apresarlo.

Incluso con las evidencias del engaño de Ibáñez y los logros obtenidos por Balmis, el virrey se niega a financiar los gastos de la expedición para continuarla por Asia. Es el mensajero, aquí representado por Salvany, quien entrega la orden venida desde España. Ciertamente, los impedimentos encontrados por Balmis en la Nueva España para el desarrollo de su misión fueron relatados por éste al monarca Carlos IV a su regreso a Madrid en 1806, quien exige a Iturrigaray dar cuenta de ello. El virrey negó todas las acusaciones en 1807 aduciendo que la vacuna ya era utilizada, previa a la llegada del médico real 


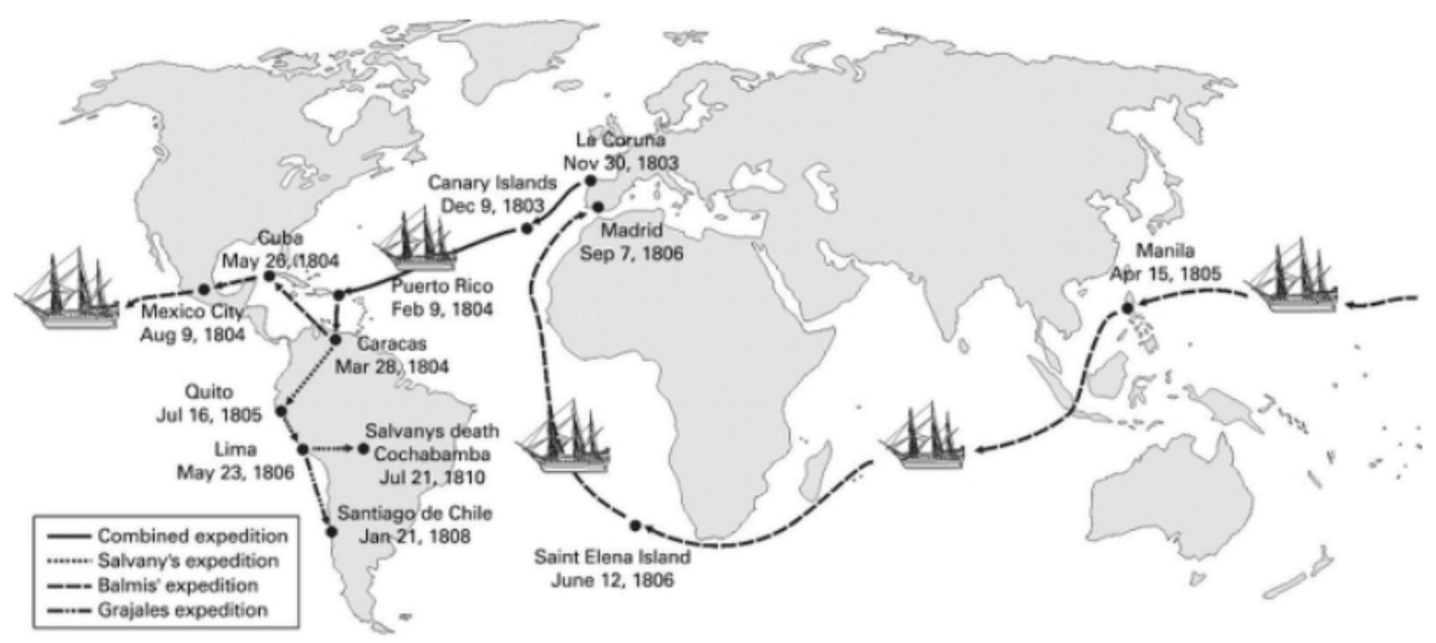

Fig. 4. Itinerario de la Real Expedición Filantrópica de la Vacuna ${ }^{13}$.

y a quien proporcionó la asistencia solicitada por su majestad ${ }^{12}$.

En efecto, ya ha sido mencionado el trabajo de vacunación en el territorio actual de México antes de la llegada de la Real Expedición, Gómez de Cruz afirma:

$$
\text { Cuando Balmis llegó }
$$
a la capital de México, después de vacunar en la península de Yucatán y de organizar la comisión que llevaría el fluido a la Capitanía de Guatemala, la vacuna ya estaba siendo impartida por los médicos locales porque la habían recibido desde Cuba ${ }^{4}$.

La historia cinematográfica termina con la instalación de Cendala y Benito en alguna casa en un puerto de su nueva patria y con el abrazo de los niños. La documentación registra que el equipo sanitario trabajó en tierras mexicanas desde su llegada a Yucatán, haciendo presencia en Veracruz, Oaxaca, Querétaro, Guanajuato y Guadalajara $^{3}$. Las Juntas de Vacuna fueron integradas por el clero católico y personal de las diferentes zonas por donde se establecieron.
Los niños traídos desde España quedaron en custodia del obispo de Puebla y fueron reclutados otros 25 pequeños, esta vez mexicanos, quienes emprendieron la segunda fase de la expedición zarpando de Acapulco en febrero de 1805 para llegar a Manila, Filipinas el 15 de abril de 1805. Isabel de Cendala se embarcó también con ellos para continuar su labor de cuidado por tierras asiáticas y regalar a esa parte del mundo el remedio para la viruela.

\section{CONCLUSIÓN}

La travesía de Balmis y su equipo se inscribe como la última de las grandes expediciones para conocer y registrar los territorios coloniales. Como ejemplo de estas son los años de exploración de Humboldt. Sin embargo, ninguna tiene el alcance en lo geográfico, sanitario, lo político, los riesgos ni en los beneficios a lo largo del tiempo para la humanidad.

En esta época donde una nueva epidemia cubre al mundo, el compromiso y vocación del personal de salud se ratifica y una vez más, se comprueba que el uso de las vacunas y su 
gratuidad, son necesarias para la salud internacional. La colaboración de distintos sectores y equipos de sanidad internacional no sólo multiplican el conocimiento, sino favorecen a sociedades enteras.

Desde 1975, en México se entrega la medaIla al mérito "Isabel de Cendala y Gómez" como reconocimiento a la labor de enfermería. El legado del Dr. Balmis e Isabel de Cendala se celebra recién al cumplirse 40 años de la erradicación de la viruela y se renueva cada año en las campañas de vacunación emprendidas por distintos países. Por ello, es menester continuar la labor altruista de estos ángeles de la salud. Así como, reconocer el valor de la inmunización con el uso de las vacunas.

\section{REFERENCIAS}

1. OMS Organización Mundial de la Salud. [internet]. Smallpox.

2. Behbehani, AM. The Smallpox Story: Life and Death of an Old Disease. American Society of Microbiology. Microbiol Rev. 1983; 47(4): 455-509.

3. Franco-Paredes C, Lammoglia L, Santos-Preciado JI. The Spanish royal philanthropic expedition to bring smallpox vaccination to the new world and Asia in the 19th Century. Confronting biological weapons. CID. 2005; 9(41): 1285-9.

4. Gómez de Cruz M. Smallpox vaccination, the estalishment of vaccination boards, and state formation in Venezuela and Cuba in the nineteenth century.
[Internet]. Florida: Florida International University; 2008.

5. López A. La rectora Isabel, al descubierto. La opinión A Coruña. 21 de noviembre de 2014.

6. De Arteaga A. Ángeles custodios. 1a. Ed. Barcelona: Ediciones B; 2010.

7. Tuells J, Ramírez Martín SM. Francisco Xavier Balmis y las Juntas de Vacuna, un ejemplo pionero para implementar la vacunación. Salud Pública en México. 2011; 2(53): 172-7.

8. Tuells J. La lista de Balmis, agosto de 1803. Vacunas. 2011; 3(12): 111-7.

9. Tuells J. El proceso de revisión a la traducción de Francisco Xavier Balmis del Tratado histórico y práctico de la vacuna, de Moreau de la Sarthe. Gac Sanit. 2012; 4(26): $372-5$

10. Balmis, FX. Archivo Histórico Nacional. Estado. Balmis. Leg. 3235 Exp. No. 1. 1801-2 en Tuells J. El proceso de revisión a la traducción de Francisco Xavier Balmis del Tratado histórico y práctico de la vacuna, de Moreau de la Sarthe. Gac Sanit. 2012; 4(26): 372-5.

11. Franco-Paredes C, Del Río C, Nava-Frías M, Rangel-Frausto S, Téllez I, Santos-Preciado JI. Bioterrorismo: aspectos clínicos y preventivos de la viruela. Salud Pública Mex. 2003; 4(45): 298-309.

12. Tuells J, Duro Torrijos JL. La segunda expedición de Balmis, revolución y vacuna. Gac Med Mex. 2013; (149): 377-84.

13. Fernández Amil I. Balmis: La legendaria expedición coruñesa que salvó a millones de personas. El Español [Internet]. 28 de 04 de 2019.

\begin{tabular}{|l|l|}
\hline & $\begin{array}{l}\text { Itza Nahomy G. Fonseca. Licenciada en Economía y Maestra en Bioética } \\
\text { por la Escuela Superior de Medicina del Instituto Politécnico Nacional en } \\
\text { Cd. de México. Diplomada en Bioética, Salud y Derecho por el Instituto de } \\
\text { Investigaciones Jurídicas, UNAM. Ha sido Jefa de Finanzas en el Hospital } \\
\text { Central de Cruz Roja Mexicana y Docente en la Escuela de Enfermería de } \\
\text { la misma institución. Ha publicado en el suplemento de salud Letra S del } \\
\text { periódico La Jornada en Cd. de México y participado en temas de bioética, } \\
\text { arte y medicina en el Foto Museo } 4 \text { Caminos. }\end{array}$ \\
\hline
\end{tabular}

Rev. Med. Cine. 2020; 16 (e), 369-378 Ediciones Universidad de Salamanca / @®@® J. Med. Mov., 2020; 16 (e), 369-378 [ 378 ] 